\title{
A Gamification Framework for Energy Conservation and Customer Engagement in Smart Cities
}

\author{
Shubhanjali Sharma, Suneel K Prasad
}

\begin{abstract}
The advancements in technology and the increased use of internet, digital business models and Internet of things (IoT) have paved a way for sustainable and inclusive cities that provide their citizens a clean and sustainable environment. Smart solutions of the smart cities focus on making the life of its citizens comfortable but they fail to make their everyday activities motivated in becoming sustainable. This paper proposes a gamification framework that aims to facilitate energy conservation and customer engagement in smart cities. By using game in a non-game context such as in this gamification framework, helps in keeping the fun element of the game intact while achieving the specified learning objective of energy efficiency. The proposed application aims at identifying energy wastages and motivates behavioral changes of the player combining team play, virtual rewards and life simulation. The paper explains various concepts of gamification and differentiates it from game-based learning. It proposes the gamification strategy, game mechanics drivers and motivators, game engine, game architecture, financial rewards and a detailed set of rules for the proposed gamification application. The application targets at promoting awareness and involvement of the players in managing their own resources, choices and behavior for a sustainable development. The paper aims at motivating the citizens and changing their behavior in a desired way.
\end{abstract}

Keywords: Energy, Gamification, Smart Cities, Sustainability.

\section{INTRODUCTION}

Gamification has gained an increased popularity in recent years, having both practical and useful application. Implementing game mechanisms such as ranking, scores, badges, levels, awards, and virtual currencies in applications and websites that are not directly related to playing fields, the developers seek to stimulate public participation and acceptable social behavior of society in various issues and areas of city life. Today, many associations and agencies have emerged that readily offer gamification design or forms

Revised Manuscript Received on February 27, 2020.

* Correspondence Author

Shubhanjali Sharma*, Symbiosis Centre for Information Technology, Symbiosis International University, Pune, India. Email: shubhanjali.sharma@associates.scit.edu

Suneel K Prasad, Professor, Symbiosis Centre for Information Technology, Symbiosis International University, Pune, India. Email: suneel@scit.edu

(C) The Authors. Published by Blue Eyes Intelligence Engineering and Sciences Publication (BEIESP). This is an open access article under the CC BY-NC-ND license (http://creativecommons.org/licenses/by-nc-nd/4.0/) of software packages helping organizations globally understand and explore gamification not only as a way to improve user experience but also as a way to motivate them.

The era of kings and queens had a strong foothold of play, games and game-based designs that was used to surpass human conditions. The convergence of internet, digital business models and geolocation-based games increased demonstration of this idea in the minds of the new generation. Every mobile application as well as website today, from social networks and meta gaming systems, use design elements like points, score, badges or leaderboards to drive players activity. This practice came to be known as gamification. Gamification is explained as the use of game mechanics in a non-entertainment environment [2].

A major enabler of gamification is its coalition with the computing technology and sensors: the emergence of smart phone, smart wearables, smart homes and smart cities generating big data helping in processing our data and tracking us in every step and effectively turning our life-world into a digital game in waiting. The vision of smart cities is to securely integrate information, communication technology and Internet of Things (IoT) in managing a city's assets. Smart cities require massive urban growth and interconnects all the three dimensions of sustainability: economic, environmental and social According to United States Department of Economics and Social Affairs (UN DESA), $68 \%$ of the world population is projected to live in urban areas by 2050[3]. With the continuing advancements in technology, the increasing population of urban areas, would require increased energy consumption. Thus, making the urban context areas to transition to renewable energy sources. This transition would require a powerful participation of all stakeholders: industries, decision makers, knowledge partners and citizens. The presence of transparent and cooperative processes can help in playing a major role in transforming all infrastructure into a zero-energy solution. The primary goal today is to incorporate change by going beyond the current practices to meet future needs. The substitution and replacement of the current infrastructure with more efficient ones is the change that is required today. This could be reflected in domestic heat system, gas grids, electricity, fuels, sewage, drinking water and solid waste. According to 2017 data [4], energy consumption in public buildings was $40 \%$ greater than that in residential buildings, while only $30 \%$ of non-residential buildings are public. Therefore, it is the need of the hour to change the focus from retrofitting older buildings to improving the energy efficiency of such buildings.

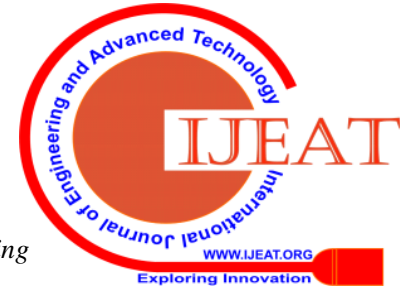


The complex problem that arises here while conserving energy is the lack of energy accountability and economic incentives for the people on conserving energy. Moreover, people lack motivation of thinking about energy conservation being pre-occupied with their everyday job tasks.

The idea of smart cities, which continues to constantly developing over the last two decades, includes many concepts and categories related to the city's transition to sustainable, ecological, reasonable development of all spheres and directions related to the well-being of citizens and the environment, interaction, development and control of all structures of the city. This task is complex and multistage; it is solved with the help of the most modern technologies and innovations; gaming can become one of them.[5]

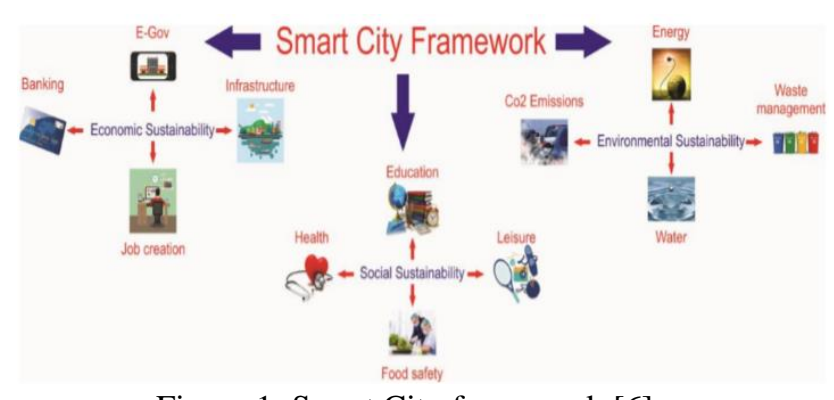

Figure 1: Smart City framework [6]

The authors in this paper propose a combined concept of smart city and gamification. They aim at defining the concept and rules of game development and use it to motivate people change their habits in a desired way. They also aim at promoting awareness and involvement of the players in managing their own resources, choices and behavior for a sustainable development.

\section{LITERATURE REIVIEW/ RELATED WORKS}

Gamification is one such area which comprises of many varieties and kinds of games. All these games have become more complex, more iterative and more real over the years but all of them have one thing that has remained constant in this evolution, it is the motivation of people to more spend time to play. These games create an imaginary simulated environment around the makes them feel as if they are inside the game. There are many research studies that discuss on the reasons which make people motivated to play games and make them stick longer to these games. Juho, Jonna and Harri [7] created a framework and examined that depending on the effect of context of usage and the specific user, gamification have positive effects on people.

Following up Schöbel and Sofia through their research state that there are many instances wherein inspite of the positive effect of a games in daily lives, many gamification projects fails [8]. The research emphasizes on adopting individual motivational and psychological needs in designing gamification elements for users.

In addition, Sebastian, Dan, Rilla and Lennart [9] invested on gamification and described the gameful phenomenon of gamification is complimentary to the playful phenomenon. They also proposed definition of gamification. The researches discuss about various new concepts such as gameful design and playful design and also clarifies a game distinction between a game and gamification.

Karl Kapp, a professor at Bloomsburg University, states that there are three critical area that makes gamification effective in different situations [10]. These areas include system quality, learner attributes and embedding right gamification into the right outcomes. He discusses that these three areas form the critical or key elements of the design of the game system that makes the system effective. Apart from these areas another important factor that a gamified solution should have is a general pickup or social use in terms of gamification implementation perspective. Adding to $\mathrm{Mr}$ Karl, Hamari and Koivisto [11] conducted a survey of the users using few of largest gamification applications, and concluded that for determining attitude of people towards gamification, social factors act as powerful predictors. Mt Karl also states that one of the critical aspects to be taken into consideration before implementing gamified solution is that the users to be aware of the gamified platform and thus few of the pre implementation steps to increase the interest of the users and make them familiar with games should be taken into consideration before the actual implementation.

These gamification applications through their interactive progress and feedback system develop a sense of inspiration among the players and keeps their motivational factor intact. Rapp [12] has named this as an ethnographic approach and has developed nine guidelines for designing a gamification system, discussing the key motivational drivers.

Kai Huotari and Juho Hamari [13], have brought in the concept of value creation touching on the points of nature of game and gamification. They have linked gamification with the service marketing concepts and have also proposed the definition of gamification in terms of gameful and user's overall value creation. They have discussed about the following four kinds of gamification providers for designing the gamification of their service:

1) A core service provider,

2) A third-party service provider,

3) Customer him/herself and

4) Another customer.

Gamification thus builds a has a special motivating feature among its users and this special motivating feature can be used in an effective to way change the perception and the way of thinking of people and draw their attention to social goals.

Many scholars have extended their researches to various applications of gamification like in education [14], the traditional way of human and computer interaction scenarios such as calibrations [15], mHealth applications [16], security awareness and training [17], government services [18] and many such areas. Sustainable development of smart cities is one such dominant area where gamification can act as an effective tool for smart governance. Researchers M R Zica, A $\mathrm{C}$ Ionica and M Leba in their research proposed the concept of using gamification in context of smart cities.[19] They have successfully integrated the concept of gamification into the lifecycle of software products. 
The research article [6], studies about the customers energy behavior through an interdisciplinary framework to increase the participation of residential customers conservation of energy.

Extending the discussion of gamification's application into energy consumption, it has been found that energy conservation in public buildings are the most challenging category to address. Literature [20] and [21], discusses that the major reason behind this is the lack of occupant's motive and lack of their individual accountability. Hence, they have proposed an IOT enabled gamification approach based on team competitions and non-monetary rewards to be used for conserving energy in public buildings. The score of the game would reflect individual's energy consumption and their willingness or unwillingness towards energy-consumption behavioral changes based on prior consumption thresholds. Multi-channel smart meters, BLE beacons, user smartphones, and the NFC tags have been used combination for energy-consumption disaggregation at the device and at the individual levels.

\section{CONCEPTUALIZING GAMIFICATION}

Gamification is defined as the use of game mechanics in non-gaming affairs engaging users in solving a particular problem. This definition of gamification can be broken down into various parts. Game mechanics is the amalgamation of rules, design and tools intended to produce a gameplay. And a gameplay is a particular way of interaction of the player of the game. It can be said that a good gameplay gives a good game and a good game in turn creates engagement.[22]

\section{A. Game-based learning vs Gamification}

Game-based learning is often used simultaneously with the word gamifications. The need of this paper involves a clear understanding of the two concepts. There are many overlapping attributes between game-based learning and gamification but two are very different concepts.

Game-based learning involves in taking the core content and the objective, thus delivering it in a fun way with the intent of teaching a particular skill or achieving a particular learning outcome using game elements. It could be defined as "A type of active learning experience within a game framework, which has specific learning objectives and measurable outcomes." [23]

On the other hand, Gamification applies game mechanics in a non-game surrounding promoting a desired behavior and driving the learning outcome. It could be defined as

"The process of adding game elements or mechanics to an experience to increase engagement or enjoyment." [24]

The difference between the two concepts are as follows:

Table 1: Difference between Game-based learning and Gamification

Game-based learning

\section{Is a Play}

As the name suggest, the primary objective here is playing the game. Puzzles, bingo games can be two prominent examples of this.

\section{Teaches a skill}

The main aim of game-based learning is learning of the objective or some specific skill. They have a defined beginning, middle and end. The activities of the game educate the learner things they need to know as they go through the game. It can be thought as a design element similar to a graphic table or video.

Here you play the game and you learn a skill.

\section{Creating new}

Game based learning entails learning of new concepts by the users and practicing the skills in a secure environment. The progress of the act directly relates to the understanding of the subject learnt. competitive side. One of the major motivating factors in gamification is the sense of progress. People like to see progress not only in games but also outside game environment. Hence progress acts as a driver in gamification. In simple terms while impending gamification one should not think about building an actual game but think about using those elements of the gaming to drive motivation

Gamification holds motivational element on the course. It motivates and encourages gamers to achieve desired learning outcome. Leader boards, badges, trophies, unlocking new content can be significant examples of this.

\section{B. Game Mechanics}

Game Mechanics is the amalgamation of distinct rules that recites the result of interactions within the system. These are a set of rules and feedback which are planned to provide fun and enjoyment to the user. They act as building blocks which when applied in the right way helps in the gamification of a non-game context. Therefore, Game mechanics form the integral and visual part of the gamification platform.

In order to develop a successful gamification platform, having a right game strategy in conjunction to the game mechanics is necessary. If we draw an analogy of game mechanics to the paints in an artist's palette then game strategy would be the artistic vision, technique and training required to start with the picture.

\section{Is a System of learning}

Gamification involves playing a game but not playing a game itself. It builds a game out of something that isn't and urges the learning ability of the player, bringing forth his

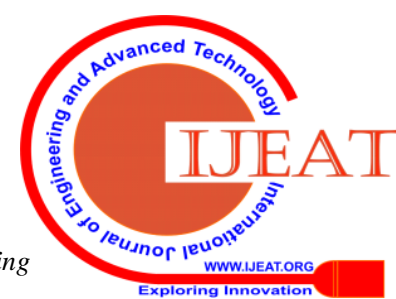



to the picture similarly having only game mechanics doesn't help in developing a great gamification application. Thus, a well-designed gamification strategy forms the base of a successful game application.

One of the major factors that drive gamification is the desired behavior of the player. The crucial element here is motivational factor that drive the player. Motivation are of two types: extrinsic and intrinsic motivation. Intrinsic motivation is the form of internal motivation done for one's own sake. Few basic intrinsic motivators include autonomy, purpose, mastery and relatedness. On the other hand, extrinsic motivation is driven by external factor in hope of winning a reward. Rewards, peer pressure and avoidance are few extrinsic motivators. [25]

These motivators are supported by elements that encourages players to use the application. These supporters form the drivers of game mechanics. [25] [26]

The key motivational drivers labeled by game mechanics are as follows:

1) Points: Points acts as a medium through which the system keeps track of the player's activities in relation to the targeted behavior in the overall gamification strategy. They are single count metrics and form the basic unit of measurement in gamification. They provide a quick feedback and status to the player and keeps them motivated to collect rewards. Thus, points address status and reward motivational driver. Players get motivated by collection and see their point count go up.

2) Badges: As a player attains certain number of predefined points they are awarded with badges. These badges give a sense of encouragement to the player and act as virtual achievements. Badges address motivational driver of reward, collection and achievement.

3) Leader boards: Point and badges achieved by a player attain their social aspect through leader boards where the points achieved by all the players are ranked in descending order having greatest number of points at the top. However, leader boards also hold a disadvantage of demotivating a new player. Leader board addresses the status motivational driver.

4) Relationships: The motivational driver on which relationship depends is connection. Humans being social beings, relationships hold a strong impact on their feelings and actions. Relationship acts as positive motivator among people and help in reducing stress. A trusted person in a member's network have more impact on his/ her everyday activities than media. Hence peer pressure is not limited to age group however it also an impact on adults. [27]

5) Challenges: This game mechanics helps to motivate people to action. This game mechanics address the mastery motivational driver.

6) Constraints: Constraints in the form of deadlines help to motivate people to action. Constraints act in conjunction to urgent optimism. These are desires to act immediately to address an obstacle combined with the belief of having a reasonable hope of success. The motivational driver addressed to overcome this game mechanics is achievement.

7) Journey: This game mechanics looks into the players personal journey includes elements to enhance the
Just like a great art cannot be made by adding many colors

experience. Few of the examples of implementation of the game mechanics include onboarding, scaffolding and progress.

Table 2: Motivators and Game mechanics drivers in gamification

\begin{tabular}{|c|c|}
\hline Motivators & Game Mechanic drivers \\
\hline Autonomy & $\begin{array}{l}\text { Customization } \\
\text { Choice } \\
\text { Freedom }\end{array}$ \\
\hline Mastery & $\begin{array}{l}\text { Levels } \\
\text { Challenges }\end{array}$ \\
\hline Purpose & $\begin{array}{l}\text { Giving / Altruism } \\
\text { Narrative } \\
\text { Greater Meaning }\end{array}$ \\
\hline Status & $\begin{array}{l}\text { Leader boards } \\
\text { Achievements }\end{array}$ \\
\hline $\begin{array}{l}\text { Social } \\
\text { Connections }\end{array}$ & $\begin{array}{l}\text { Suggest similar users } \\
\text { Cooperative "play" }\end{array}$ \\
\hline Rewards & $\begin{array}{l}\text { Points } \\
\text { Badges } \\
\text { Achievements }\end{array}$ \\
\hline Peer Pressure & $\begin{array}{l}\text { Peer review / feedback / } \\
\text { grading systems } \\
\text { Boasting / Bragging system } \\
\text { Competitive "play" }\end{array}$ \\
\hline Avoidance & $\begin{array}{l}\text { Lose Points } \\
\text { Lose Status } \\
\text { Game Over }\end{array}$ \\
\hline Scarcity & $\begin{array}{l}\text { Exclusive / Unique Rewards } \\
\text { Reward Schedules }\end{array}$ \\
\hline Fun & $\begin{array}{l}\text { Real Games } \\
\text { Quiz's } \\
\text { Competitions }\end{array}$ \\
\hline
\end{tabular}

Therefore, Game Mechanics helps to motivate and engage players and helps to accomplish business goals.[24]

\section{Gamification Strategy}

The gamification concept is of two kinds: Structural gamification and Content gamification.

Structural gamification: It is structing the content of the game. The native content of the game does not change here, however, the way of presentation of the content is game like. Since, it involves minor content rework, the progress of the game is independent of the content of the application. As an example, if we take into consideration the musical chair game, every time the music stops the player need to deliver a content which can be anything and thus it qualifies to be a structural gamification. In this type of gamification, the content does not become the game but delivery of the content becomes a game. It generally uses template-based approach and which can plug in with the native content. Structural gamification is cost effective and time efficient. [28] Content gamification: This is considered to be a serious game template where the content of the game is turned into a game. It forms a one-time structure which is created for a specific objective and takes longer time to develop. 
In content gamification the delivery is dependent on the application of the content. As an example, if we take into considering the game of business, the player in this game learns the basics of real estate business by buying cities and making their own houses on them and thus making their decisions thereby learning from consequences.[28]

In order to decide which gamification strategy to adopt, both these gamification concepts need to be analyzed on the following parameters: Development Cost, Time, Scalability, Reusability and Internal Resource Engagement.

Table 3: Difference between Structural gamification and Content gamification

\begin{tabular}{|c|l|l|}
\hline Approach & \multicolumn{1}{|c|}{$\begin{array}{c}\text { Structural } \\
\text { Gamification } \\
\text { Rentent }\end{array}$} & $\begin{array}{l}\text { Content } \\
\text { gamification } \\
\text { (Serious Games) }\end{array}$ \\
\hline $\begin{array}{c}\text { Minor content } \\
\text { rework of the } \\
\text { design } \\
\text { instructions has to } \\
\text { be done }\end{array}$ & $\begin{array}{l}\text { Major content } \\
\text { rework in terms } \\
\text { of arrangement } \\
\text { has to be done }\end{array}$ \\
\hline $\begin{array}{c}\text { Re-Usability } \\
\text { developed can be } \\
\text { re-used for all } \\
\text { kinds of training }\end{array}$ & $\begin{array}{l}\text { This template } \\
\text { once developed } \\
\text { cannot be reused. } \\
\text { It can only be } \\
\text { used to for the } \\
\text { specific learning } \\
\text { objective for } \\
\text { which it was } \\
\text { developed }\end{array}$ \\
\hline $\begin{array}{c}\text { Development } \\
\text { Cost }\end{array}$ & $\begin{array}{l}\text { Development cost } \\
\text { is comparatively } \\
\text { low }\end{array}$ & $\begin{array}{l}\text { Development cost } \\
\text { is comparatively } \\
\text { high }\end{array}$ \\
\hline $\begin{array}{c}\text { Development } \\
\text { Time }\end{array}$ & $\begin{array}{l}\text { It takes } \\
\text { comparatively } \\
\text { less time to } \\
\text { develop, is } \\
\text { quicker to deploy } \\
\text { and required } \\
\text { minimum UAT } \\
\text { time }\end{array}$ & $\begin{array}{l}\text { It takes longer } \\
\text { time to develop, } \\
\text { prototype UAT } \\
\text { testing takes } \\
\text { longer time }\end{array}$ \\
\hline Best Used & $\begin{array}{l}\text { Driving } \\
\text { engagement for } \\
\text { Mandatory } \\
\text { /Compliance/New } \\
\text { Hire }\end{array}$ & $\begin{array}{l}\text { New Skill } \\
\text { Acquisition }\end{array}$ \\
\hline
\end{tabular}

\section{Game engines}

In order to implement gamification, there should be a common platform that provides graphics, artificial intelligence, sound, network capability, video and physics. In order to implement these functionalities together huge amount of skills, resources and time are required. Thus, to overcome these issues, all the major functions available today is bundled together in the form of a game engine. A game engine acts as a basic framework for the gamification applications. They offer an incredible advantage to the developers over starting from scratch in building an application. Few of the proprietary game engines are as follows:

1) Unity is a closed-source and cross platform game development application by Unity Technologies. It is used to develop video games for web plugins, desktop platforms, consoles and mobile devices. Unity is basically

- a game engine, which helps to run the game in different environments

- an application, where different visible parts of your game can be put together with a graphical preview

- and a code editor

It can handle from a massively-multi player online game all the way down to a simple kart racer. Three- and two-dimensional games can be built using Unity by manipulating them in three and two dimensions. It supports scripts written in C\#, Boo or UnityScript. [29]

2) CryEngine is a powerful real-time game development platform developed by a German developer, Crytek. The full engine source code and all the engine features are available for free: no license fee, no royalties and hidden fees. It supports Xbox One, PlayStation 4, Windows PC, Oculus Rift platforms. The engine is a visually beautiful having beautiful graphics and life like characters. The fifth version of CryEngine supports virtual reality consisting of astonishing visual effects such as cloud rendering system which gives the clouds a full 3D spatial rendering and a realistic visualization of fog and other weather effects. CryEngine also through its question and answer forum called CryEngine answers, clears the doubts and provides a smooth and comfortable experience to its users. [29]

3) Unreal engine 4 is a game engine developed by Epic Games. Unreal engine 4 comes up with graphics that give gaming experience a realistic approach. It supports development across multiple platform such as Xbox One, PS4, PC, iOS, Android, Mac OS X, Linux, and VR. It offers workflow features and a deep toolset with a complete $\mathrm{C}++$ source code. It is a free to use engine however five percent royalty fee needs to be paid. It supports blueprint visual scripting technology which helps even the non-programmers to write code and create games. [29].

4) Cocos2D is an open source cross-platform open source game framework which is known for developing mobile games. The platform is known for its speed, stability and ease of use. It is written in $\mathrm{C}++/$ Javascript/Lua. Cocos 2D claims themselves to be World's number 1 Open-Source Game Development Platform. It is one of the best platforms to develop two-dimensional games providing the developer greater access over the code and full autonomy over the projects.[29].

5) Blender is a free and opensource 3D suite used real interactive content. It is a fast and powerful graphics and animation tool. It is written in $\mathrm{C}++$ language form scratch and supports features such as Python scripting and OpenAL 3D sound. To control the movement and display of objects, the engine uses a system of logic bricks and can also extend via a set of Python bindings.[30].

6) BigWorld is a game engine that is widely used for the development of massively multiplayer online games (MMO) and virtual worlds. It uses game logic and AI to develop applications and is based on the Python scripting language. It supports windows PC and browser, and is available on iOS, Xbox 360 and Play Station 3 via network API.

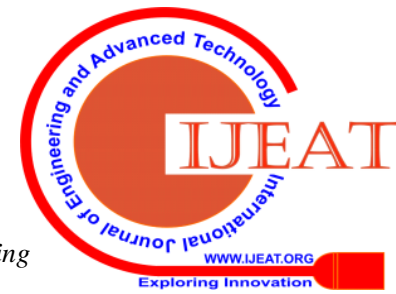


The architecture of BigWorld game engine takes a lot of complexity out of building a multiplayer game, which allows games designers to get assets into the game quickly. This makes BigWorld popular not only among the small development teams but also among professional game developers. [31].

7) Leadwerks is the easiest game engine to make $3 \mathrm{D}$ games powered by OpenGL 4.0. It is a cross platform game engine and majorly focuses on the ease of use and learning. It supports both windows and Linux along with OS X support in development. The platform is written in $\mathrm{C}++$ language and uses OpenGL 4.0 graphics API. It supports Lau and C++ programming and provides project templates for Visual Studio.[32].

8) HeroEngine is a $3 D$ game engine that uses client server technology platform for building massively multiplayer online games (MMO) and virtual worlds. The engine features collaborative development and has online creation feature. It builds a client-server platform and integrates the core networking systems into a single, unified game creation and editing environment. It also works with technologies from third party vendors. [33].

With the increase in gamification platforms since last decade, there are many game engines present but each of these have their own advantages and disadvantages and choosing a right game engine is crucial part of the development of the gamification application. [34][35][36]

\section{IMPLEMENTING GAMIFICATION}

\section{A. How to design the gamification experience?}

Designing a great gamification experience is a challenging task. Just having a replication of best strategies and tools is not sufficient for increasing player's motivation. However, it is very important to choose the right gamification ideas and the right techniques to implement these ideas.[38] Therefore, in order to build a motivated and sufficient gamification experience, techniques which will form the pillars of such an experience are:

1) Choose a gamification template that completely projects the gamification story: It very important to choose a template that echo's a storyline. The story line can be anything based on the objective for which the game is being developed. It could be anything ranging from millionaire quiz game or mountain expedition or city development or finding the way back home to anything. However, the only concern here is that the storyline should connect with the audience and must excite their learner base. The look and feel of the application must be comfortable enough for the age group that it targets. Adding multiple storylines for different initiative into the same game or increasing complexity level are few ways that keep the game alive so in turn keeps pace with the players motivation.

2) Choosing right mix of game mechanics drivers: There are various game mechanics drivers available as discussed earlier. Using these drivers together in the right way is very important. Using to many drivers together can become a big spoiler, however using them in right mix can overwhelm the players. The key here is to be simple and move towards complexity unless you want to do so.
3) Choosing a good gamification template does not stand to be an end all solution: It is very important to understand that increasing players motivation and their engagement are main objective of gamification but not the only objective. It is important to keep the seriousness to learning intact with the game. The content is important too and the right balance between the two is to be maintained. The key to good gamification template is good content.

4) Choosing significant gamification drivers: The players analyse their performance in the game through the points and badges they achieve. Therefore, it is very important to keep the right mix of simple and complex assessments in order to keep up the motivation of the player. At the same time the badges should reflect that they are meaningful and difficult to achieve.

\section{B. How will gamification help in the conservation of energy in smart cities?}

The problem of unsustainable energy consumption and energy wastage is a global issue today. Wee Siaw Chui and Choong Weng Wai in their research [39] have claimed that the relation of human behavior to energy issues can be effective in the conservation of energy. The concept of gamification can so, act as a great motivation for us human towards the conservation of energy. Game has a fun element which creates an enjoyable environment for humans and in turn contributes in this objective. The research [40] also claims that this concept has been a proven effective way of motivating individuals on the particular behavior. And until we have engagement of users in energy conservation, sustainable development cannot be attained. Simoes, Redondo and Vilas [40] in their research state, "Although the concept has been explored primarily in the marketing area, the potential of its application has been extended to other areas such as Health, Environment, Government or Education." Thus, gamification of environmental issues is an effective approach towards sustainable development.

A smart city being beyond technology, being populated by people is raised by the contribution of the citizens. To build a successful smart city model it is important to understand its concepts and benefits. Smart homes, smart buildings are the major aspect of smart cities. Further, applying the concept of gamification in smart cities would motivate the player to have a sustainable development. The level of human interaction involved in these smart cities will decide the success of gamification applications implemented. The higher the interaction level the more the success factor. [18]

\section{PROPOSED GAME}

Considering the discussion in the earlier section, this research aims to propose a game application based on the concept of gamification that could be successfully implemented in the smart city model.

Concerning this few of the unique features of the proposed game would be: 
1) $100 \%$ free game- It would be a freemium game wherein the players will not be charged any amount for players. Also, there would not be any hidden charges in application charges, on contrary the game would act as a way of saving money.

2) Play with friends- The game would use the collaboration element wherein the players could either compete with their friends or could work together in teams.

3) Smart home devices- The game would be connected to the smart devices of the player's home helping them to measure and monitor their energy performance.

The connectivity of the gamification application and the smart home can be explained through the below diagram.

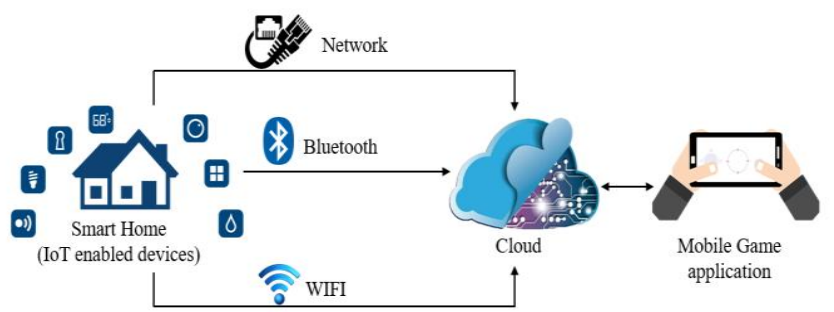

Figure 2: Connectivity architecture of the gamification application

\section{A. Strategy of the proposed game}

The proposed game is a serious (strategy) game. As discussed earlier, content gamification or serious games are designed with a primary purpose apart from entertainment. The serious adjective in strategy serious game refers to game developed for attainment of sustainable development of smart cities for smart governance.

The idea of the game is based on a simulation strategy combined with real home and energy grid data which would help the players in tracking their energy performance. It deals with the autonomous decision making and skills of the player

\section{B. Mechanics and Motivators in the proposed game}

The proposed game includes following drivers of game mechanics:

\begin{tabular}{|c|c|c|c|}
\hline Autonmy & Mastery & Status & $\begin{array}{c}\text { Social } \\
\text { Connections }\end{array}$ \\
\hline $\begin{array}{l}\text { - Choice } \\
\text { - Freedom }\end{array}$ & $\begin{array}{l}\text { - Levels } \\
\text { - Challenges }\end{array}$ & $\begin{array}{l}\text { - Leaderbaords } \\
\text { - Achievements }\end{array}$ & $\begin{array}{l}\text { - Suggest } \\
\text { similar users } \\
\text { - Coopreative } \\
\text { "play" }\end{array}$ \\
\hline Rewards & Peer Pressure & Scarcity & Fun \\
\hline $\begin{array}{l}\text { - Points } \\
\text { - Badges } \\
\text { - Achievements }\end{array}$ & $\begin{array}{l}\text { - Peer review } \\
\text { - Competitive } \\
\text { "play" }\end{array}$ & $\begin{array}{l}\text { - Exclusive } \\
\text { Rewards } \\
\text { - Unique } \\
\text { Rewards }\end{array}$ & $\begin{array}{l}\text { - Real Games } \\
\text { - Competitions }\end{array}$ \\
\hline
\end{tabular}

Figure 3: Motivators and drivers of the proposed game

Besides these drivers, proposed game involves following features:

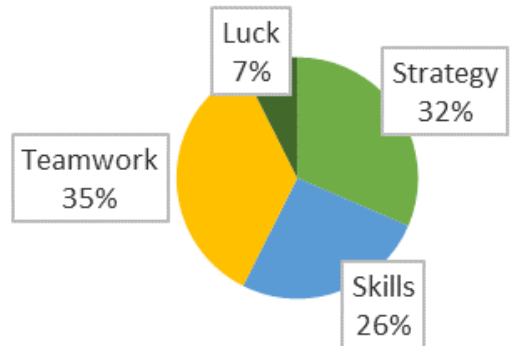

Figure 4: Features of the proposed game

\section{Engine for the proposed game}

, Based on analysis done by Humberto and Giner in their research [41], Unreal Engine 4 would be proposed for the development of our prospective gamification application. The game attributes supported by this engine are all that is required in our gamification framework.

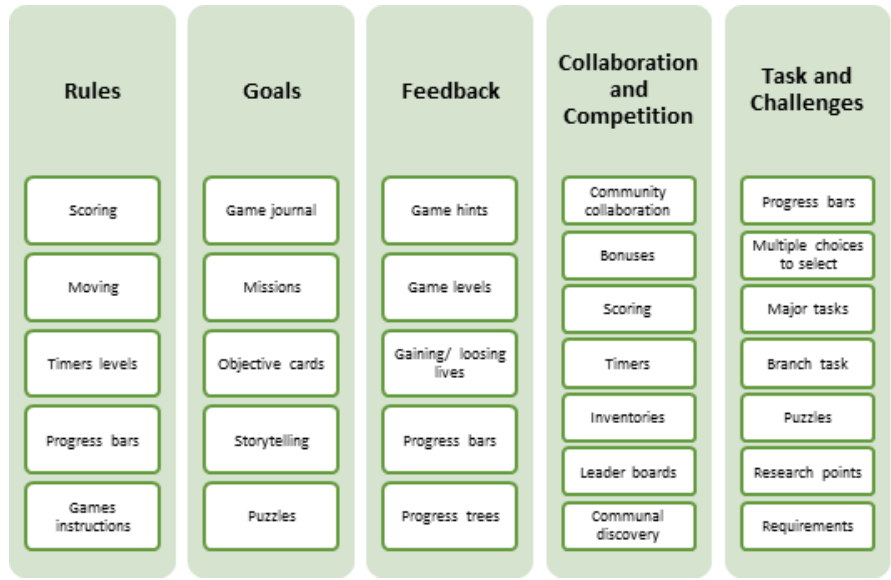

Figure 5: Game Categories with its attributes supported by Unreal Engine 4

\section{Architecture of the proposed game}

The proposed game is similar to games like clash of clans and the settlers, where the player is supposed to build a strategy. The architecture of the game would consist of two windows.

The first window would motivate the players to build their own smart city by adding energy efficient systems in their city and the aim would be to make the city energy efficient. The major advantage of this window is to make citizens aware of the various energy efficient alternatives available in real world. It will motivate the players to take different initiatives in their city such as implementation of an LED bulb instead of a 100-watt bulb which would help them earn additional points. In order to level up in the game, the players would be required to decrease the energy consumption of their city to a predefined threshold. Competitive edge would be added to the game by adding game elements like leader board and badges. The second window would be linked to real world. The application would be connected to the smart meter and the smart devices of the player's house. The application will geo-track the player automatically through their smart meter and will assign certain time restricted goals to them.

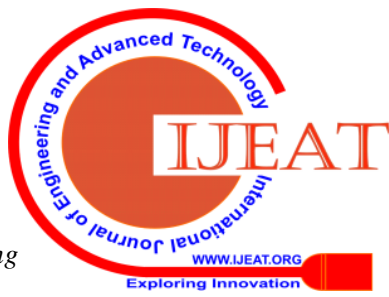


These goals will be related to lowering the real time energy consumption of the players house.

Another important game element that would be present in the second window is collaboration. Additional bonus points would also be awarded for referring the application to a friend. The idea behind this concept is to make the application popular and accelerate team work of the players. The game would then by using google based APIs would assign additional special tasks to the player for limited timeframe that needs to be performed by a player in team in the distinct neighborhood to fetch him additional rewards. The second window would act as a daily motivational factor for the player to login into the game and achieve their targets. The attribute of team play involving going outside to meet up with other players for bonus resources, and competition would add a fun experience to the player.

The authors have proposed this game to make the player gain a fun experience while facing various challenges of the
Table 4: Architecture of the proposed game Game Architecture
Window 1-Strategy game

- Build energy efficient neighborhood

- Awareness of energy efficient alternatives

- Use skills and strategy

- Level ups and gain rewards
Window 2-Real time game

- Smart home devices

- Real time energy conservation

- Earn rewards

- Team play and community contribution

\section{E. Financial rewards in the proposed game}

Introduction of monetary benefits in the game for the players would act as a motivational driver for the players.

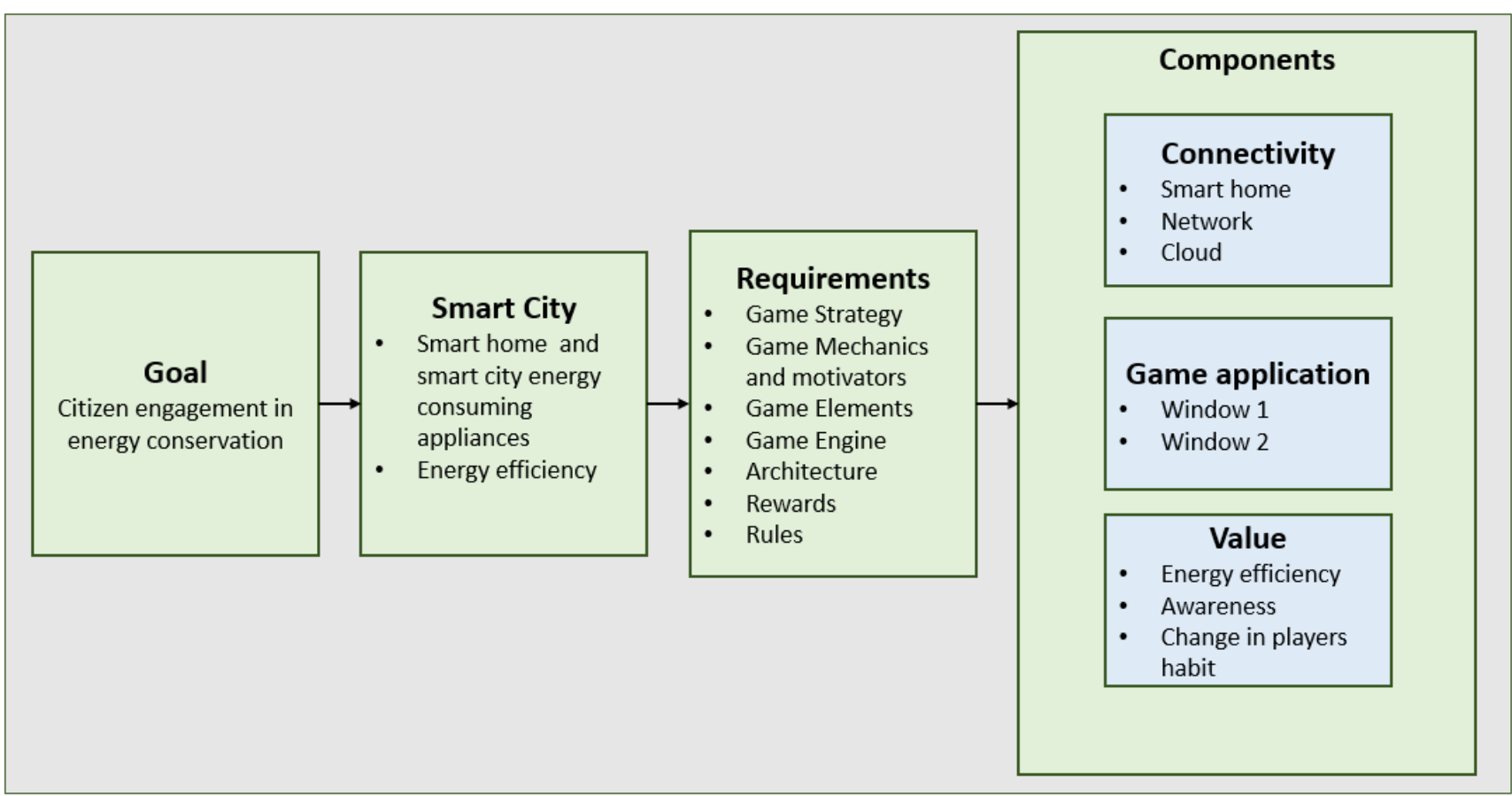

Figure 6: Conceptual diagram of the proposed framework for gamified energy application

game. The different everyday initiative taken by

the player to gain rewards of the game would over a period of time make these activities and tasks their habit which would not only lower the energy utilization while playing the game but also while not playing the game. With more and more participation this would help improve energy sustainability target achievement.
The game could promise the player of delivering prizes and rewards for their small efforts towards conservation of energy and sustainable development. Following can be few steps that could be incorporated:

1) A threshold needs to be decided for the reward.

2) On attainment of the threshold, player be provided with monetary awards.

3) These monetary awards could be in terms of cash prizes or vouchers which could be arranged by corporate sponsorship where corporates would see their respective brand value.

4)Tie up with government could be made and electricity bill relaxations could be provided under the ambit of smart governance policies and framework.

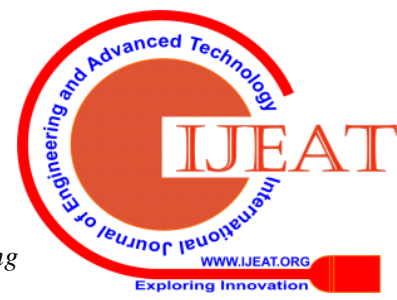




\section{F. Rules of the proposed game}

The proposed game is a level-based game wherein the players motivation is increased by performing tasks and crossing the levels. Below are rules of the game for level 1 to level 3 of the proposed game for each Window.

For Window 1: This window deals with the best practices to be adopted by the player.

Table 5: Levels of Window 1 of the proposed game

\begin{tabular}{|c|c|}
\hline \multicolumn{2}{|r|}{ Window 1} \\
\hline Level 1 & $\begin{array}{l}\text { - Build a house } \\
\text { - Use renewable and energy efficient } \\
\text { materials for house building } \\
\text { - Build triple glazed solar windows in the } \\
\text { house } \\
\text { - Buy and install curtains } \\
\text { - Buy a fuel-efficient vehicle }\end{array}$ \\
\hline Level 2 & $\begin{array}{l}\text { - Add energy efficient lights in the house } \\
\text { - Buy and install smart home devices from } \\
\text { repository } \\
\text { - Buy and install multi fuel stove in the } \\
\text { house } \\
\text { - Buy and install heat recycling ventilators } \\
\text { - Build energy stations in the city }\end{array}$ \\
\hline Level 3 & $\begin{array}{l}\text { - Buy and install solar panels in your } \\
\text { house } \\
\text { - Upgrade the quality of house curtains } \\
\text { - Buy and install energy efficient boilers } \\
\text { - Plant tree in the garden area } \\
\text { - Build a wind farm in the city } \\
\text { - Set up public buildings in the } \\
\quad \text { neighborhood }\end{array}$ \\
\hline
\end{tabular}

For window 2: Neighborhood electricity and energy grid map and live energy consumption data should be made open to public by the government so that humans can come up together and offer community contribution.

Table 6: Levels of Window 2 of the proposed game

\begin{tabular}{|c|c|}
\hline \multicolumn{2}{|r|}{ Window 2} \\
\hline $\begin{array}{l}\text { Level 1- Live } \\
\text { home energy } \\
\text { consumption }\end{array}$ & $\begin{array}{l}\text { Points will be allocated for completing each of the } \\
\text { below tasks. } \\
\text { - Allow the game APIs to access the live energy } \\
\text { data of the players home } \\
\text { - Switch off the unnecessary switch on lights } \\
\text { - Switch off unused switched on plug points } \\
\text { - Switch off plugs connected to charged devices } \\
\text { On achieving the threshold points level } 1 \text { is cleared. }\end{array}$ \\
\hline $\begin{array}{l}\text { Level 2- Live } \\
\text { home energy } \\
\text { consumption }\end{array}$ & $\begin{array}{l}\text { Points will be allocated for completing each of the } \\
\text { below tasks. } \\
\text { - Removing curtains from the window during day } \\
\text { time and using natural sunlight instead to home } \\
\text { lighting } \\
\text { - Replace incandescent bulbs with energy-efficient } \\
\text { ones } \\
\text { - Using cold water in washing machines instead of } \\
\text { hot. } \\
\text { - Setting the water heater to maximum of } 120 \\
\text { degrees } \\
\text { On achieving the threshold points level } 2 \text { is cleared. }\end{array}$ \\
\hline $\begin{array}{l}\text { Level 3- } \\
\text { Community } \\
\text { collaboration }\end{array}$ & $\begin{array}{l}\text { At this level the collaboration with neighborhood } \\
\text { friends start. Points will be allocated for completing } \\
\text { each of the below tasks. } \\
\text { - Add in neighborhood friends in your game } \\
\text { - Collaboration tasks } \\
\text { - Remind and notify the friend to switch }\end{array}$ \\
\hline
\end{tabular}

off unnecessary lights in his home

- Remind and notify the friend to switch off unused plug points

- Switch off light of public buildings

- Switch off street lights during day time

- Individual tasks

- Regularly cleaning the air conditioner filters

- Refer the game to friends

- Keep your home's energy consumption less than that of neighbors

On achieving the threshold points level 3 is cleared.

\section{CONCLUSION}

In this paper, we have proposed a gamification framework for increasing citizen engagement in conservation of energy. We have discussed the game strategy, game mechanics, motivators, game engine, financial rewards and rules to be used while building the gamification application. This framework is a means for changing the traditional social energy initiatives to fun and interesting and in turn increasing citizen engagement by developing an extended relationship with the players and keeping the motivational factors intact. Therefore, this framework is a smart city approach towards sustainable development.

The proposed gamification framework could also be extended to other environmental concerns such as waste management, water conservation where in the same gamification application could be used to extend services to these areas. The gamification application built using this framework would also generate huge amount of user data which could further be analyzed through various analytical tools and can be used to improve the existing application.

\section{REFERENCES}

1. Deterding, S., Dixon, D., Khaled, R. and Nacke, L. (2011), "From Game Design Elements to Game-fulness. Defining "Gamification"', Proceedings of the 15th International Academic MindTrek Conference Envisioning Future Media Environments, pp. 9-15.

2. Davis, K. and Singh, S. (2015), "Digital badges in afterschool learning. Documenting the perspectives and experiences of students and educators", Computers \& Education, Vol. 88, pp. 72-83.

3. United Nattions Department of Economic and Social Affairs

Available:https://www.un.org/development/desa/en/news/population/2 018-revision-of-world-urbanization-prospects.html [Accessed: 25th November 2019]

4. Cao, Xiaodong \& Xilei, Dai \& Liu, Junjie. (2016). Building energy-consumption status worldwide and the state-of-the-art technologies for zero-energy buildings during the past decade. Energy and Buildings.

5. Nacke, L. E., \& Deterding, S.The maturing of gamification research, Computers in Human Behavior (2017)

6. M R Zica, A C Ionica and M Leba(2018): Gamification in the context of smart cities. In: IOP Conf. Series: Materials Science and Engineering 294 (2018) 012045

7. Hamari, J., Koivisto, J., \& Sarsa, H. (2014). Does Gamification Work? A Literature Review of Empirical Studies on Gamification. In proceedings of the 47th Hawaii International Conference on System Sciences, Hawaii, USA, January 6-9, 2014.

8. Schöbel, S. \& Söllner, M. (2016): How to Gamify Information Systems Adapting Gamification to Individual User Preferences. In: European Conference on Information Systems (ECIS), Istanbul, Turkey.

9. Sebastian Deterding, Dan Dixon, Rilla Khaled and Lennart Nackle: From Game Design Elements to Gamefulness: Defining "Gamification"

10. Karl Kapp, Youtube channel: Growth Engineering,

Available: https://www.youtube.com/watch?v=KdnQhMD3HCw [Accessed: 4th October 2019] 


\section{A Gamification Framework for Energy Conservation and Customer Engagement in Smart Cities}

11. Hamari, J., \& Koivisto, J. (2013): Social motivations to use gamification: an empirical study of gamifying exercise. In Proceedings of the 21st European Conference on Information Systems, Utrecht, Netherlands, June 5-8, 2013

12. Rapp, A. (2015). Designing interactive systems through a game lens: An ethnographic approach. Computers in Human Behavior

13. Kai Huotari, Juho Hamar: Defining Gamification - A Service Marketing Perspective. Helsinki Institute for Information Technology HIIT, Aalto University

14. Kapp, K. M. (2012). The gamification of learning and instruction: game-based methods and strategies for training and education. John Wiley \& Sons

15. Flatla, D. R., Gutwin, C., Nacke, L. E., Bateman, S., \& Mandryk, R. L. (2011, October). Calibration games: making calibration tasks enjoyable by adding motivating game elements. In Proceedings of the 24th annual ACM symposium on User interface software and technology (pp. 403-412). ACM

16. Aaron S Miller, Joseph A Cafazzo, Emily Seto(2014): A game plan: Gamification design principles in mHealth applications for chronic disease management. In: Health Informatics Journal 1-10

17. Eyvind Garder B Gjertsen(2016): Use of Gamification in Security Awareness and Training Programs, Norwegian University of Science and Technology

18. J.Tuomas Harviainen and Lobna Hassan 2019) Governmental Service Gamification: Central Principles. In: International Journal of Innovation in the Digital Economy (IJIDE)

19. Tarek AlSkaif, Ioannis Lampropoulos, Machteld van den Broek, Wilfried van Sark (2018): Gamification-based framework for engagement of residential customers in energy applications. Energy and Resources Group, Copernicus Institute of Sustainable Development, Utrecht University (UU), The Netherlands

20. Thanasis G. Papaioannou, Dimos Kotsopoulos, Cleopatra Bardaki, Stavros Lounis , Nikos Dimitriou, George Boultadakis,Anastasia Garbi , Anthony Schoofs(2017): IoT-Enabled Gamification for Energy Conservation in Public Buildings

21. Thanasis G. Papaioannou, Nikos Dimitriou , Kostas Vasilakis , Anthony Schoofs , Manolis Nikiforakis, Fabian Pursche, Nikolay Deliyski, Amr Taha, Dimosthenis Kotsopoulos, Cleopatra Bardaki , Sarantis Kotsilitis and Anastasia Garbi (2018): An IoT-Based Gamified Approach for Reducing Occupants' Energy Wastage in Public Buildings

22. Youtube channel: Inspire Lab,

Available:https://www.youtube.com/watch?v=-N-jMSymzBM [Online] [Accessed: 4th October 2019]

23. Calli Wright, Game-based Learning vs Gamification: What's the Difference? Available:

https://blog.mindresearch.org/blog/game-based-learning-vs-gamificatio

[Accessed: 10th October 2019]

24. Andrzej Marczewski, Game mechanics in gamification, (January 14, 2013)Available:https://www.gamified.uk/2013/01/14/game-mechanicsin-gamification/

[Accessed: 10th October 2019]

25. Raph Koster, Game Designer and author of A Theory of Fun for Game Design. Available: https://www.theoryoffun.com/

26. Eric Zimmerman and Katie Salen, Game Designer and author of Rules of Play.(November 4, 2013)

27. Kumar, Janaki. (2013). Gamification at Work: Designing Engaging Business Software. 528-537. 10.1007/978-3-642-39241-2_58.

28. Training Leader's Guide to Leverage Gamification Successfully for Organizational Learning by Aman Deep Dubey, (August 17, 2017)

29. Cocos: Cocos2D. Available: http://www.cocos2d.org [Accessed: 4th November 2019]

30. Wartmann, C.: Blender Book: Free 3D Graphics Software for the Web and Video. Vol. 1, Starch Press (2011)

31. Pty, B.: Server Programming Guide. Australia, BigWorld Pty Ltd, (2012)

32. Corporation, V.: Leadwerks Game Engine. Available: http://store.steampowered. com/app/251810 [Accessed: 4th November 2019]

33. Fabrik, I.: HeroEngine. Available: http://www.heroengine.com [Accessed: 4th November 2019]

34. Burke, B.: Gartner Redefines Gamification. Available: http://blogs.gartner.com/brian_burke/2014/04/04/gartner-redefines-gam ification

[Accessed: 4th November 2019]

35. Lameras, P.: Essential Features of Serious Games Design in Higher Education. Society for research into higher education, pp. 3-22 (2015)

36. McLean, P., Scott, B.: Competencies for Learning Design: A Review of the Literature and a Proposed Framework. British Journal of Educational Technology, 42(4), pp. 557-572 (2011)
37. Ali, Zulfiqar \& Usman, Muhammad. (2016). A framework for game engine selection for gamification and serious games. 1199-1207. 10.1109/FTC.2016.7821753.

38.Training Leader's Guide- How to Design a Successful Gamification Experience for Your Learners? Available: https://www.learntech.in/how-to-design-your-gamification-experience/

39.Wee Siaw Chui1, Choong Weng Wai2 (2017),Gamification motivating users' energy conservation behaviour, International Journal of Real Estate Studies, Volume 11 Number 1

40.Simoes, J., Redondo, R. D., and Vilas, A. F. (2013). A Social Gamification Framework for a K-6 Learning Platform. Computers in Human Behavior, 29, 345 - 353.

41.Humberto Marín-Vega, Giner Alor-Hernandez, Ramón Zatarain-Cabada, M. Lucía Barrón-Estrada (2016), Analyzing Proprietary Games Engines for Developing Educational and Serious Games, pp. 27-35; rec. 2016-07-17; acc. 2016-09-18

42.D. Geelen, D. Keyson, S. Boess, H. Brezet, Exploring the use of a game to stimulate energy saving in households, J. Des. Res. 14 (1-2) (2012) 102-120 10.

43.F. Grossberg, M. Wolfson, S. Mazur-Stommen, K. Farley, S. Nadel, Gamified energy efficiency programs, American Council for an Energy-Efficient Economy, Washington, DC, 2015 Report (B1501).

44.A.L. Beck, K. Lakkaraju, V. Rai, Small is big: interactive trumps passive information in breaking information barriers and impacting behavioral antecedents, PLOS ONE 12 (1) (2017) e0169326.

\section{AUTHORS PROFILE}

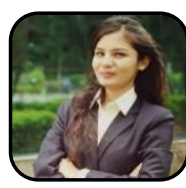

Shubhanjali Sharma, is a graduate in Computer Science and Engineering. She is currently pursuing her MBA in Information Technology Business Management from Symbiosis Centre for Information Technology, Symbiosis International University. She is a student of Information Security bearing ISO 27001 Lead Auditor certification and Six Sigma Green belt certification. She has keen interest in sustainable development of her neighborhood and has been part of design thinking projects for sustainable development and paper presentation on improved sustainable lifestyle at Symbiosis Centre for Information Technology. Her current research interest lies in the areas of Cyber Security, emerging IT innovations, IoT, Blockchain and Strategy and Governance issues related to sustainable development.

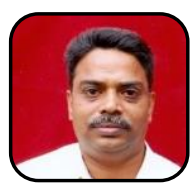

Suneel K Prasad, is a Professor at the Faculty of Computer Studies, Symbiosis Centre for Information Technology, Symbiosis International University. He pursued his engineering in Electronics \& Communication, and completed a Master of Engineering in Computer Science \& Engineering from the Indian Institute of Science. He has more than 35 years of experience in Defense (IT \& Telecom Operations), DRDO (Electronic Warfare Systems Development), Corporate (IT Systems Deployment \& Operations) and Academics. His current research interest lies in the area of Business Process Automation, Social Media Analytics for Humanitarian Response and other emerging IT Innovations like Gamification and IOT to solve Governance and Social \& Environmental Challenges. 